\title{
A AÇÃo NA PERSPECTIVA do DIREITO FUNDAMENTAL DE ACESSO À TUTELA JURISDICIONAL
}

\author{
THE ACTION IN THE PERSPECTIVE OF THE FUNDAMENTAL RIGHT OF ACCESS \\ TO JUDICIAL PROTECTION
}

Leonardo Beduschi ${ }^{1}$

SUMÁRIO: Introdução; 1. Percurso histórico do conceito de Ação; 2. Ação no Código de Processo Civil de 1973. Críticas à teoria eclética; 3. A Ação hoje; Considerações finais; Referências das fontes citadas.

RESUMO: O artigo tem por objetivo construir um breve painel acerca da evolução histórica do conceito de Ação, partindo do direito romano clássico até a preocupação atual em assegurar uma participação efetiva por meio do Processo, relacionando o conceito de Ação ao dever de proteção dos Direitos Fundamentais. Valendo-se dessa perspectiva, conclui-se que, superadas social e historicamente as teorias que discutiam sobre a abstração e a autonomia do direito de Ação, é indispensável pensar a Ação sob a ótica do efetivo acesso à ordem jurídica justa, e não apenas em relação ao direito formal de acesso ao judiciário.

Palavras-chave: Ação; Acesso à Justiça; Teoria eclética; Direitos fundamentais.

ABSTRACT: The article aims to develop a short panel about the historical evolution of the concept of Action, starting from the classical Roman law until the current concern to ensure effective participation through the process and the duty of protection of fundamental rights. Drawing on this perspective, it is concluded that,

1 Graduado em Direito pela Universidade Regional de Blumenau (FURB). Especialista em Direito Processual Civil pela Universidade Federal de Santa Catarina (UFSC) e em Direito Constitucional pela Universidade do Sul de Santa Catarina (UNISUL). Mestrando em Ciência Jurídica na Universidade do Vale do Itajaí (UNIVALI). Professor titular de Direito Processual Civil e Teoria Geral do Processo na Universidade Regional de Blumenau (FURB). leobeduschi@brturbo.com.br 
BEDUSCHI, Leonardo. A ação na perspectiva do direito fundamental de acesso à tutela jurisdicional. Revista Eletrônica Direito e Política, Programa de Pós-Graduação Stricto Sensu em Ciência Jurídica da UNIVALI, Itajaí, v.10, n.2, 10 quadrimestre de 2015. Disponível em: www.univali.br/direitoepolitica ISSN 1980-7791.

historically and socially overcomed the theories that discuss the abstraction and the autonomy of the right of Action, it is essential to think the Action from the perspective of effective access to fair legal system, and not only in relation to the right formal access to the judiciary.

Keywords: Action, Access to Justice; Eclectic theory; Fundamental Rights.

\section{INTRODUÇÃO}

Um instituto do Direito Processual Civil ${ }^{2}$ que evidencia de forma clara, na evolução histórica do seu conceito, a influência dos valores adotados pelo texto constitucional, notadamente o abandono da neutralidade da Jurisdição e do Processo e a preocupação com os Direitos Fundamentais, é a Ação.

Isso porque se pode afirmar que os estudos doutrinários acerca da Ação foram determinantes para a conquista da autonomia do Direito Processual Civil e do caráter científico deste, com todos os aspectos positivos e negativos dessa constatação.

É interessante destacar que, nessa trajetória conceitual, vão se descortinando diversos panoramas que evidenciam ora o amadurecimento de uma categoria jurídica de importância vital para a Ciência Jurídica, ora uma excessiva abstração dispensada no tratamento de um instituto de evidente relevância prática. Ao fim, o que se espera demonstrar é que, a exemplo do que ocorre em outras disciplinas e categorias, a teoria dos Direitos Fundamentais apresenta-se como o prisma mais efetivo (o uso do adjetivo "correto", aqui, é incabível) para a conexão definitiva entre a Ação e o acesso à justiça.

Não se pode falar, na maioria dos casos, em teorias corretas ou incorretas, porque, desde que dotadas de lógica e coerência, são todas substancialmente corretas, ainda que não possuam mais correspondência com o Estado contemporâneo ${ }^{3}$. As teorias não podem ser descoladas do momento histórico no qual foram concebidas.

Em outras palavras, na opinião de Gustavo Zagrebelsky, hoje se tem uma ideia de direito que parece exigir uma profunda renovação de numerosas concepções jurídicas que operam na prática, pois atualmente se questiona o que há por trás do direito dos textos oficiais, ou seja, "as ideias gerais, a mentalidade, os métodos, as

\footnotetext{
${ }^{2}$ Por Direito Processo Civil entenda-se o conjunto de princípios e normas destinados a reger a solução de conflitos mediante o exercício do poder estatal. As quatro grandes categorias jurídicas que compõe o "núcleo estrutural do direito processual (os seus institutos fundamentais)" são a Jurisdição, a Ação, a defesa e o Processo. (DINARMARCO, Cândido Rangel. Instituições de direito processual civil. 4. ed. São Paulo: Malheiros, 2004. Vol. I. P. 37 e 40)
}

3 MARINONI, Luiz Guilherme. Teoria geral do Processo, São Paulo: RT, 2006, p. 22. 
BEDUSCHI, Leonardo. A ação na perspectiva do direito fundamental de acesso à tutela jurisdicional. Revista Eletrônica Direito e Política, Programa de Pós-Graduação Stricto Sensu em Ciência Jurídica da UNIVALI, Itajaí, v.10, n.2, 10 quadrimestre de 2015. Disponível em: www.univali.br/direitoepolitica ISSN 1980-7791.

expectativas, as estruturas de pensamento e os estilos jurídicos herdados do passado que já não encontram justificação no presente". Se poderia dizer, simplesmente, que a "ideia de direito que o atual Estado constitucional implica não entrou plenamente no ar que respiram os juristas" ${ }^{4}$.

Portanto, afigura-se importante, para os objetivos do presente trabalho, uma análise, ainda que sumária, da evolução do instituto e das teorias que buscaram explicar o direito de Ação.

A doutrina, de uma forma, geral, justifica a importância do estudo da Ação na vedação, pela ordem jurídica imposta pelo Estado, da autotutela, ou seja, na vedação da prática da justiça de mãos próprias ${ }^{5}$. Como consequência dessa proibição, que é essencial a própria configuração do Estado e da sociedade moderna, surge para o primeiro a obrigação de prestar Jurisdição, cujo conceito operacional será melhor analisando no item seguinte, a todos os cidadãos. Essa concepção é pacífica na doutrina ${ }^{6}$.

Partindo dessa premissa, e dentro dos estreitos limites dessa exposição, se afigura necessário expor, em rápidas linhas, as ideias centrais das principais teorias que buscaram conceituar a Ação, bem como as críticas doutrinárias mais comuns feitas a cada uma delas.

\section{PERCURSO HISTÓRICO DO CONCEITO DE AÇÃO}

Para a denominada teoria civilista (ou imanentista), não há Ação sem direito, não há direito sem Ação e a Ação segue a natureza do direito. Ou seja, a Ação era o próprio direito material "colocado em movimento, a reagir contra a ameaça ou a violação"7. A Ação, para essa teoria, era concebida como um direito nascido da violação do direito material, que era exercido contra o violador. Contudo, esse "direito novo" não possuía autonomia alguma em relação ao direito violado, tanto que era exercido

${ }^{4}$ ZAGREBELSKY, Gustavo. El Derecho Dúctil: ley, derechos, justicia. Tradução de Marina Gascón. 6. ed. Madrid: Editorial Trotta, 2005. Título original: Il diritto mitte. Legge diritti giustizia, p. 9-10.

5 Atualmente, no Brasil, a autotutela (ou autodefesa) é tipificada no art. 345 do Código Penal Brasileiro, como "exercício arbitrário das próprias razões".

${ }^{6}$ Nesse sentido, dentre muitos outros: SILVA, Ovídio Araújo Baptista da; GOMES, Fábio Luiz. Teoria geral do Processo civil. 4. ed. rev. e atual. com a recente reforma processual. São Paulo : Revista dos Tribunais, 2006. P. 90, MARINONI, Luiz Guilherme. Teoria geral do Processo, p. 157, THEODORO JÚNIOR, Humberto. Curso de direito processual civil: teoria geral do direito processual civil e Processo de conhecimento.53. ed. rev. e atual., Rio de Janeiro : Forense, 2012. P. 69. PINHO, Humberto Dalla Bernardina de. Direito processual civil contemporâneo. Volume I. 4. ed. $2^{\mathrm{a}}$ tir. São Paulo: Saraiva, 2012. P. 177. SANTOS, Moacyr Amaral; KÖHNEN, Maria Beatriz Amaral Santos. Primeiras linhas de direito processual civil. 27. ed. São Paulo : Saraiva, 2010. P. 155.

7 SILVA, Ovídio Araújo Baptista da; GOMES, Fábio Luiz. Teoria geral do Processo civil. P. 94-95. 
BEDUSCHI, Leonardo. A ação na perspectiva do direito fundamental de acesso à tutela jurisdicional. Revista Eletrônica Direito e Política, Programa de Pós-Graduação Stricto Sensu em Ciência Jurídica da UNIVALI, Itajaí, v.10, n.2, 10 quadrimestre de 2015. Disponível em: www.univali.br/direitoepolitica ISSN 1980-7791.

contra quem havia violado o direito material ${ }^{8}$.

É, dentre todas as teorias, a mais antiga, e foi delineada por Friedrich Von Savigny em seu conhecido "Sistema do direito romano atual", baseando-se na definição do jurisconsulto romano Celso de que a Ação nada mais é do que o direito de pedir em juízo o que nos é devido ${ }^{9}$.

Foi exatamente no contexto da teoria civilista no qual se deu a polêmica entre os romanistas alemães Bernhard Windscheid e Theodor Muther, que se tornou célebre na segunda metade do século $\mathrm{XIX}^{10}$ e por força da qual emergiu a demonstração da existência de um direito à tutela jurisdicional exercido contra o Estado ${ }^{11}$, bem como a separação entre os planos do direito material e processual, "deixando para trás a antiga concepção que unia direito material e Ação"12.

Essa polêmica teve por objeto a concepção romana da actio, expressão que até os dias atuais é traduzida comumente por Ação. Em síntese, Bernhard Windscheid defendeu que a actio romana equivaleria à "pretensão" moderna (Anspruch), que brota do direito, e não ao que hoje é denominado de "Ação" (Klage ou Klagerecht), pois a actio não era um meio de defesa de um direito, mas sim o próprio direito, que se caracterizaria pela faculdade de realizar a própria vontade por meio de uma perseguição em juízo. Assim, a actio seria o termo romano para designar o que alguém pode exigir de outrem, pois a ordenação romana era uma ordenação de pretensões que poderiam ser perseguidas judicialmente, e não de direitos ${ }^{13}$.

\footnotetext{
8 MARINONI, Luiz Guilherme. Teoria geral do Processo, p. 158.

${ }_{9}$ Nihil aliud est actio quam ius, quod sibi debeatur, in judicio persequendi. (SILVA, Ovídio Araújo Baptista da; GOMES, Fábio Luiz. Teoria geral do Processo civil, p. 94). Na Itália e na França, a doutrina acrescentava, a esse aforismo, a locução vel quod suum est, que significa "ou o que é seu", a fim de explicitar que a definição abrangia não apenas os direitos obrigacionais, mas também os direitos reais (MARINONI, Luiz Guilherme. Teoria geral do Processo, p. 157-158).
}

10 Os textos principais dessa polêmica foram condensados por Tomás Banzaf em WINDSCHEID, Bernard e MUTHER, Theodor. Polemica sobre la "Actio". Buenos Aires: Ediciones Juridicas EuropaAmerica (EJEA), 1974. Vide também SILVA, Ovídio Araújo Baptista da; GOMES, Fábio Luiz. Teoria geral do Processo civil. P. 96.

${ }^{11}$ SILVA, Ovídio Araújo Baptista da; GOMES, Fábio Luiz. Teoria geral do Processo civil, p. 95.

12 MARINONI, Luiz Guilherme. Teoria geral do Processo, p. 162. Para Couture, a separação do direito e da Ação constituiu para a ciência do Processo, um fenômeno análogo ao que representou para a física a divisão do átomo (COUTURE, Eduardo J. Fundamentos del derecho procesal civil. 3. ed. póst. Buenos Aires: Depalma, 1973).

13 A análise da polêmica entre Windscheid e Muther foi efetuada com base nas seguintes obras: WINDSCHEID, Bernard e MUTHER, Theodor. Polemica sobre la "Actio". Buenos Aires: Ediciones Juridicas Europa-America (EJEA), 1974. SANTOS, Moacyr Amaral; KÖHNEN, Maria Beatriz Amaral Santos. Primeiras linhas de direito processual civil, p. 158. SILVA, Ovídio Araújo Baptista da; GOMES, Fábio Luiz. Teoria geral do Processo civil, p. 96-101. MARINONI, Luiz Guilherme. Teoria geral do Processo, p. 159-162. 
BEDUSCHI, Leonardo. A ação na perspectiva do direito fundamental de acesso à tutela jurisdicional. Revista Eletrônica Direito e Política, Programa de Pós-Graduação Stricto Sensu em Ciência Jurídica da UNIVALI, Itajaí, v.10, n.2, 10 quadrimestre de 2015. Disponível em: www.univali.br/direitoepolitica ISSN 1980-7791.

Theodor Muther, por seu turno, partindo do pressuposto que ordenamento jurídico romano era composto por direitos e que aquele que pedia a fórmula ao pretor também tinha um direito subjetivo (um "direito originário", que era o fundamento do direito à fórmula), afirmou que o obrigado perante o direito originário era 0 particular, enquanto que o obrigado diante do direito à fórmula é o Estado, "sendo o direito privado pressuposto do direito contra o Estado; os dois direitos coexistiriam, ainda que o direito contra o Estado existisse para proteger o direito privado"14. Esse direito contra o Estado seria o equivalente romano da Ação (Klagerecht) atual, que também é autônomo em relação ao direito material que visa a proteger. Em suma, para Theodor Muther, o direito de agir não se confunde com o direito material, mas tem ele como pressuposto ${ }^{15}$.

Bernhard Windscheid acolheu em parte as críticas de Theodor Muther e admitiu a existência de uma Ação processual paralela à pretensão de direito material, concluindo, por fim, que a pretensão de direito material, atualmente, convive com o que ele chamou de "direito à tutela do Estado". Entretanto, Bernhard Windscheid defendeu-se afirmando que seu crítico desvirtuou parcialmente sua concepção original, pois suas ideias haviam sido desenvolvidas sob o ângulo do direito material, e não do ponto de vista do direito processual $^{16}$.

A célebre polêmica entre os dois romanistas permitiu vislumbrar a autonomia do direito de Ação em relação ao direito material. O passo doutrinário seguinte seria a concepção da Ação como um direito autônomo e concreto, também conhecida como teoria do direito concreto à tutela jurisdicional. Essa teoria, cronologicamente, é posterior à teoria da Ação como direito abstrato, já que as obras de Degenkolb e Plósz precederam a obra de Adolph Wach e foram por ele criticadas. Contudo, por uma questão metodológica (e também, por que não dizê-lo, pedagógica), afigura-se mais interessante a análise da teoria concretista em primeiro lugar, já que a teoria da Ação como direito abstrato é cientificamente mais avançada do que aquela ${ }^{17}$.

Para os concretistas, dentre os quais se destaca Adolph Wach, a Ação é um direito autônomo por não ter, necessariamente, fundamento num direito subjetivo ameaçado ou violado, pois a Ação pode ser empregada para obter uma simples

\footnotetext{
14 MARINONI, Luiz Guilherme. Teoria geral do Processo, p. 162.

15 Para Muther, "no âmbito do direito romano, deve a actio ser entendida, num primeiro momento, como ato bilateral com que se iniciava o Processo, pois, na mais antiga das ações da lei (a legis actio sacramento), ninguém poderia vir a juízo desacompanhado da parte adversa (cum aliquo). Como actio provinha de agere (comparecer, falar, agir diante do pretor), também indicava a própria fórmula escrita desse rito. Extintas as ações da lei e o solene comparecimento diante do pretor, agere e actio ficaram designando o ato mediante o qual o autor iniciava o Processo; ou, antes, todo o Processo que precedia a lide in judicio e cujo último termo era a concessão da fórmula". (SILVA, Ovídio Araújo Baptista da; GOMES, Fábio Luiz. Teoria geral do Processo civil, p. 98).

16 SILVA, Ovídio Araújo Baptista da; GOMES, Fábio Luiz. Teoria geral do Processo civil, p. 99.

17 SILVA, Ovídio Araújo Baptista da; GOMES, Fábio Luiz. Teoria geral do Processo civil, p. 102.
} 
BEDUSCHI, Leonardo. A ação na perspectiva do direito fundamental de acesso à tutela jurisdicional. Revista Eletrônica Direito e Política, Programa de Pós-Graduação Stricto Sensu em Ciência Jurídica da UNIVALI, Itajaí, v.10, n.2, 10 quadrimestre de 2015. Disponível em: www.univali.br/direitoepolitica ISSN 1980-7791.

declaração de inexistência ou de inexistência de relação jurídica (Ação declaratória). Para Wach, somente existiria efetivamente tutela jurisdicional (prestada pelo Estado em resposta ao pedido do autor) em caso de sentença favorável, ou seja, o direito de Ação "depende da concorrência de requisitos de direito material, as chamadas condições da Ação, e de direito formal, os chamados pressupostos processuais, sem os quais não se concebe uma tal sentença e não haverá Ação". Oskar Von Büllow também adotou essa teoria, sustentando que a Ação é o direito a uma sentença justa $^{18}$.

Com exceção da Ação declaratória negativa (que Wach utilizava para criticar a teoria imanentista), Wach condicionava a Ação ao direito subjetivo material, "que só poderia conduzir a uma sentença favorável". O referido autor impunha três condições para a Ação, quais sejam: 1) a existência de um direito violado ou ameaçado de violação (legítimo interesse); 2) a necessidade de que o direito violado ou ameaçado seja do próprio autor (legitimação); e 3) a possibilidade jurídica do pedido, "ou a adequação do direito ao ordenamento jurídico concreto, materializado em fatos-tipos previamente determinados ${ }^{\prime 19}$.

Ainda segundo Wach, "a tutela jurídica é prestada pela sentença favorável". E prossegue:

Ela é prestada ao autor, na Ação declaratória de existência e na Ação declaratória de inexistência, quando a sentença reconhecer, respectivamente, a existência ou a inexistência da relação jurídica, isto é, quando a sentença for de procedência, mas será prestada ao réu quando a sentença for de improcedência. Ou seja, o direito à tutela jurídica requer uma sentença favorável. Na verdade, Wach distinguia a pretensão à tutela jurídica da pretensão à sentença, sendo a primeira devida a uma das partes e a segunda a ambas. Ainda que o autor e o réu tivessem pretensão à sentença, a pretensão à tutela jurídica dependia de uma sentença favorável ${ }^{20}$.

As lições de Adolph Wach espalharam-se pela Europa continental e alcançaram a América Latina. No Brasil, a influência de Wach manifestou-se por meio de Chiovenda, seu discípulo, e pelos discípulos deste, notadamente Calamandrei e Liebman ${ }^{21}$.

Chiovenda elaborou uma variante dessa teoria que ficou conhecida como teoria da

18 SANTOS, Moacyr Amaral; KÖHNEN, Maria Beatriz Amaral Santos. Primeiras linhas de direito processual civil, p. 158-159.

${ }^{19}$ SILVA, Ovídio Araújo Baptista da; GOMES, Fábio Luiz. Teoria geral do Processo civil, p. 104.

${ }^{20}$ MARINONI, Luiz Guilherme. Teoria geral do Processo, p. 165.

${ }^{21}$ SILVA, Ovídio Araújo Baptista da; GOMES, Fábio Luiz. Teoria geral do Processo civil, p. 103. 
BEDUSCHI, Leonardo. A ação na perspectiva do direito fundamental de acesso à tutela jurisdicional. Revista Eletrônica Direito e Política, Programa de Pós-Graduação Stricto Sensu em Ciência Jurídica da UNIVALI, Itajaí, v.10, n.2, $1^{0}$ quadrimestre de 2015. Disponível em: www.univali.br/direitoepolitica ISSN 1980-7791.

Ação como direito potestativo. Para Chiovenda, a Ação não se dirige contra o Estado, mas contra o adversário, que nada pode fazer em relação ao exercício desse direito. Em outras palavras, a teoria chiovendiana afirma que a Ação é um direito potestativo (ou um poder, Kann Rechte), que produz efeitos em favor de um sujeito e gera ônus para outro, o qual nada deve fazer e nada pode fazer a fim de evitar tal efeito, ficando apenas sujeito a sua produção ${ }^{22}$. Assim, para Chiovenda, a Ação teria natureza privada ou pública, conforme a lei a qual buscar atuar ${ }^{23}$.

Nas palavras do autor em questão:

A Ação é, portanto, o poder jurídico de dar vida à condição para a atuação da vontade da lei. Definição que, bem examinada, coincide com a das fontes: nihil aliud est actio quam ius persequendi iudicio quod sibi debetur (Inst. IV, 6, pr); em que é evidentíssima a contraposição do direito de conseguir o bem que nos é devido mediante o juízo (ius iudicio persequendi).

A Ação é um poder que nos assiste em face do adversário em relação a quem se produz o efeito jurídico da atuação da lei. 0 adversário não é obrigado a coisa nenhuma diante desse poder, simplesmente lhe está sujeito. Com seu próprio exercício exaure-se a Ação, sem que o adversário nada possa fazer, quer para impedi-la, quer para satisfazê-la. Sua natureza é privada ou pública, consoante a vontade da lei, cuja atuação determina,

\footnotetext{
22 CHIOVENDA, Giuseppe. Instituições de direito processual civil. Campinas : Bookseller, 1998. 1v. Título original: Instituizioni di Diritto Processuale Civile. P. 42. Essa concepção de Chiovenda tem por fundamento o seu conceito Jurisdição. Para Chiovenda, a função jurisdicional tem por escopo a atuação da vontade da lei, a fim de manter a ordem jurídica. Por isso, a manifestação de vontade do titular do direito de Ação, provocando a Jurisdição, "é suficiente para que esta entre em atividade, atuando a vontade da lei em relação ao adversário, sem que este possa impedir que a atividade jurisdicional se exerça. Como a provocação da Jurisdição pelo titular do direito de Ação é suficiente para que a função jurisdicional se exerça, pode-se dizer que aquela provocação é condição do exercício da Jurisdição, ou seja, é condição para a atuação da vontade da lei. E, assim, conclui Chiovenda, que a Ação é poder jurídico de realizar a condição necessária para a atuação da vontade da lei". (SANTOS, Moacyr Amaral; KÖHNEN, Maria Beatriz Amaral Santos. Primeiras linhas de direito processual civil, p. 159-160).
}

23 "Para Chiovenda, a Ação se destina a provocar um efeito jurídico contra o adversário, derivado da sentença de procedência que faz atuar a lei. Segundo Chiovenda, somente é investido da Ação aquele cuja demanda é acolhida. Portanto, a Ação é um poder em face do adversário que depende de uma sentença favorável, isto é, que necessita de uma sentença que declare a vontade da lei, uma vez que é dela que serão projetados efeitos jurídicos. A Ação, a levar à atuação da lei (na hipótese de sentença de procedência) e, por consequência, fazer produzir efeitos jurídicos sobre o réu, estabelece uma relação de poder entre o autor e o réu. Ao precisar o seu conceito de Ação, Chiovenda esclarece que a Ação é um poder em face do adversário, mais do que um poder contra o adversário. Com isso, quer dizer que a Ação não exige obrigação alguma, pois o adversário, diante da Ação, não é obrigado a nada, mas apenas fica sujeito aos efeitos jurídicos da atuação da lei (em caso de sentença favorável)" (MARINONI, Luiz Guilherme. Teoria geral do Processo, p. 165-166). 
BEDUSCHI, Leonardo. A ação na perspectiva do direito fundamental de acesso à tutela jurisdicional. Revista Eletrônica Direito e Política, Programa de Pós-Graduação Stricto Sensu em Ciência Jurídica da UNIVALI, Itajaí, v.10, n.2, 10 quadrimestre de 2015. Disponível em: www.univali.br/direitoepolitica ISSN 1980-7791.

seja de natureza privada ou pública ${ }^{24}$.

Degenkolb, na Alemanha, e Plósz, na Hungria, desenvolveram uma teoria que criticou essa concepção da Ação como o direito de obter uma providência jurisdicional favorável em sentido concreto, que ficou conhecida como teria da Ação no sentido abstrato. Para essa concepção, não basta distinguir a Ação do direito material por ela veiculado (pois, segundo essa lógica, somente existiria a Ação quando a sentença fosse favorável); o direito de acionar o réu exige apenas que o autor faça referência a um interesse seu protegido em abstrato pelo direito, ficando - Estado obrigado a exercer atividade jurisdicional e a proferir uma sentença, ainda que desfavorável ${ }^{25}$. Ou seja, para essa teoria, para a configuração do direito de Ação pouco importa que o autor tenha ou não razão ${ }^{26}$.

Para se compreender essa teoria, é fundamental vislumbrar a existência de dois interesses diversos: o interesse tutelado pelo direito e o interesse à obtenção da tutela jurisdicional (ou interesse secundário, ou interesse social especial, ou interesse abstrato e geral). Este interesse secundário, em comparação com 0 interesse primário haurido do direito material, não varia, permanecendo o mesmo ${ }^{27}$.

A consequência direta dessa concepção da Ação é a constatação de que o direito de Ação é um direito abstrato e geral, que não está necessariamente vinculado à existência de um direito subjetivo material, não dependendo nem mesmo de um "elemento subjetivo" (fé, crença) que se refira à existência de um direito subjetivo. Basta, para o exercício do direito de Ação, que o autor se refira a um interesse primário juridicamente protegido ${ }^{28}$.

Segundo Ugo Rocco, o direito de Ação é um direito subjetivo público e está incluído, também, dentre os interesses cívicos, pois tem como objeto uma prestação positiva por parte do Estado, não estando necessariamente condicionado à existência de um direito material. "Precisamente por motivo dessa característica, trata-se de um direito contra o Estado, não contra o adversário". E finaliza o mencionado autor

\footnotetext{
${ }^{24}$ CHIOVENDA, Giuseppe. Instituições de direito processual civil. P. 42.

25 SANTOS, Moacyr Amaral; KÖHNEN, Maria Beatriz Amaral Santos. Primeiras linhas de direito processual civil, p. 160-161.

${ }^{26}$ SILVA, Ovídio Araújo Baptista da; GOMES, Fábio Luiz. Teoria geral do Processo civil, p. 108.

27 Segundo a lição de Alfredo Rocco, "[...] o interesse secundário tem por objeto uma utilidade secundária, ou um bem especial que serve de meio para alcançar a utilidade principal. 'A intervenção do Estado para a realização dos interesses tutelados, não só por sua importância como também porque implica a atividade de um sujeito diverso dos interesses principais, é uma utilidade que se busca de modo especial, adquirindo, assim, uma existência autônoma e distinta à das utilidades principais a que em última análise se refere'"'. (Sentenza civile. Milano: Giuffre, 1962, apud SANTOS, Moacyr Amaral; KÖHNEN, Maria Beatriz Amaral Santos. Primeiras linhas de direito processual civil, p. 161).
}

28 SANTOS, Moacyr Amaral; KÖHNEN, Maria Beatriz Amaral Santos. Primeiras linhas de direito processual civil, p. 162. 
BEDUSCHI, Leonardo. A ação na perspectiva do direito fundamental de acesso à tutela jurisdicional. Revista Eletrônica Direito e Política, Programa de Pós-Graduação Stricto Sensu em Ciência Jurídica da UNIVALI, Itajaí, v.10, n.2, 10 quadrimestre de 2015. Disponível em: www.univali.br/direitoepolitica ISSN 1980-7791.

conceituando Ação como "o direito público subjetivo do cidadão contra o Estado, e só contra o Estado, tendo por conteúdo substancial o interesse abstrato na intervenção do Estado, para a eliminação dos obstáculos" que possam surgir à efetiva realização dos interesses tutelados ${ }^{29}$.

No Brasil, contudo, foi a teoria exposta por Enrico Tullio Liebman em 24 de novembro 1949 na aula inaugural na Universidade de Turim ${ }^{30}$ que acabou sendo incorporada pelo Código de Processo Civil e também pela maior parte da doutrina. Costumam-se apontar três causas fundamentais para tal acolhida:

A primeira consistiu no impacto e profunda impressão do fundador da Escola de Processo de São Paulo sobre os discípulos que o cercaram, sem dúvida uma plêiade de juristas que logo passaram a difundir as ideias do mestre, tornando-se também eles mestres de escol. A obras de Alfredo Buzaid, de José Frederico Marques e de Machado Guimarães - para citar apenas alguns deles - demonstram a procedência da afirmação. A segunda causa decorre diretamente da primeira: a liderança intelectual exercida pelos discípulos de Liebman fez com que o espectro de suas ideias atingisse o âmbito nacional; com isso, outros grandes processualistas mais jovens formaram-se sob esta influência. Finalmente, o fato de haver o nosso Código vigente ter adotado orientação consentânea ao pensamento de Liebman certamente desestimulou uma dissensão maior ${ }^{31}$.

Para Liebman, a Ação, como direito de provocar a Jurisdição, deve ser tida como o direito de provocar o julgamento do pedido, ou seja, a decisão sobre a lide, ou a análise do mérito. A Ação não compete a qualquer pessoa, pois o seu caráter abstrato não pode ser entendido com a extensão que lhe é normalmente atribuída. A Ação, apesar de abstrata, engloba apenas as hipóteses nas quais o pedido for julgado procedente ou improcedente ${ }^{32}$.

\footnotetext{
${ }^{29}$ ROCCO, Ugo. Tratato di diritto processuale civilie, 2a Ed, Uter, 1966, apud SANTOS, Moacyr Amaral; KÖHNEN, Maria Beatriz Amaral Santos. Primeiras linhas de direito processual civil, p. 162-163.

${ }^{30}$ MARINONI, Luiz Guilherme. Teoria geral do Processo, p. 168.

${ }^{31}$ SILVA, Ovídio Araújo Baptista da; GOMES, Fábio Luiz. Teoria geral do Processo civil, p. 117.

32 SILVA, Ovídio Araújo Baptista da; GOMES, Fábio Luiz. Teoria geral do Processo civil, p. 115. Ovídio Baptista e Fábio Gomes expõem também que, para que seja bem compreendida a teoria eclética, é preciso esclarecer a posição de Liebman acerca do conceito de lide, mérito e Jurisdição. "A lide é conceituada por Liebman como o conflito efetivo ou virtual de pedidos contraditórios. Não aceita ele, por conseguinte, o conceito carneluttiano, com toda razão afirmando, apoiado em Calamandrei, que, se o conflito de interesses não entrar para o Processo tal como verificou-se na vida real, descaberá ao juiz conhecer do que não constitui objeto do pedido. Já o conceito de mérito identifica-se com o de lide. Incluem-se no mérito todas as questões que, de qualquer forma, se refiram à controvérsia existente entre as partes e submetida ao conhecimento do juiz, cuja solução pode levar ao julgamento do pedido, quer para acolhê-lo, quer para rejeitá-lo. Entende Liebman por Jurisdição a
} 
BEDUSCHI, Leonardo. A ação na perspectiva do direito fundamental de acesso à tutela jurisdicional. Revista Eletrônica Direito e Política, Programa de Pós-Graduação Stricto Sensu em Ciência Jurídica da UNIVALI, Itajaí, v.10, n.2, 10 quadrimestre de 2015. Disponível em: www.univali.br/direitoepolitica ISSN 1980-7791.

O que importa, para Liebman, para que a Ação reste configurada e o mérito possa ser analisado, é a presença de determinados requisitos, denominados condições da Ação, que são a possibilidade jurídica do pedido, a legitimidade ad causam e o interesse de agir $^{33}$.

A possibilidade jurídica do pedido consiste na previsibilidade em abstrato, pelo direito objetivo, da pretensão exarada pelo autor. $O$ interesse de agir ou utilidade/necessidade da tutela jurisdicional decorrem da ameaça ou da violação do direito subjetivo. Finalmente, para a teoria eclética, a legitimidade corresponde à identidade entre os sujeitos da relação processual e os sujeitos da relação material discutida no Processo ${ }^{34}$.

Em relação ao interesse de agir, segundo a concepção da teoria aqui estudada, este decorre da necessidade de obter através do Processo a proteção do interesse substancial, ou seja, pressupõe a assertiva de lesão desse interesse a aptidão do provimento pedido a protegê-lo e satisfazê-lo ${ }^{35}$. Tais condições seriam requisitos para a existência da Ação, tanto que, ausente qualquer delas, há o que Liebman denominou carência de Ação.

Sua teoria foi chamada de eclética por representar uma tentativa de sintetizar as duas principais teorias que a precederam, ou seja, a teoria da Ação como direito concreto e como direito abstrato ${ }^{36}$.

atividade do Poder Judiciário que viabiliza, na prática, a realização da ordem jurídica mediante a aplicação do direito objetivo às relações humanas intersubjetivas. E essa realização só é conseguida pela decisão de mérito". (op. cit., loc. cit.).

33 Segundo Luiz Guilherme Marinoni, na $3^{a}$ edição do seu Manuale di diritto processuale civile, Liebman abandonou a categoria da "impossibilidade jurídica do pedido". A partir daí, ao tratar do interesse de agir, passou a dizer que "seria uma inutilidade [faltaria interesse de agir] proceder ao exame do pedido para conceder ou negar o provimento postulado" quando o provimento "não pudesse ser proferido, porque não admitido por lei". Assim, Liebman inseriu a ideia da impossibilidade jurídica do pedido na ausência de interesse de agir. (Teoria geral do Processo, p. 169). Tal ocorreu porque o único exemplo utilizado por Liebman para ilustrar um pedido juridicamente impossível era o divórcio; entretanto, em 1970, na Itália, foi aprovada a introdução do divórcio no ordenamento jurídico italiano, razão pela qual esse exemplo não mais pode ser utilizado pelo doutrinador (op. cit., p. 173-174).

${ }^{34}$ SILVA, Ovídio Araújo Baptista da; GOMES, Fábio Luiz. Teoria geral do Processo civil, p. 113.

${ }^{35}$ MARIONI, Luiz Guilherme. Teoria geral do Processo, p. 169.

${ }^{36}$ Ou seja, para Liebman a Ação não depende de uma sentença de procedência, mas requer a presença das condições da Ação. Portanto, Liebman conclui que quando o juiz reconhece que as condições da Ação não estão presentes, e, assim, se nega a julgar o mérito, não há verdadeiro exercício da Jurisdição. Entretanto, Liebman chegou a afirmar que não há Jurisdição no caso de carência de Ação e também que somente tem direito à tutela jurisdicional aquele que tem razão. (MARIONI, Luiz Guilherme. Teoria geral do Processo, p. 171). 


\section{AÇÃo NO Código de PROCESSO CIVIL DE 1973. CRÍtICAS À TEORIA ECLÉTICA}

A acolhida da teoria eclética pelo direito objetivo brasileiro pode ser facilmente comprovada pela leitura, por exemplo, dos arts. 30 e 267, inc. VI, do Código de Processo Civil. De acordo com a norma contida nesse último, o Processo será extinto sem resolução do mérito "quando não concorrer qualquer das condições da Ação, como a possibilidade jurídica, a legitimidade das partes e o interesse processual".

As condições da Ação também estão previstas no art. 295, incs. II e III, e o seu parágrafo único, inc. III, do Código de Processo Civil.

A teoria eclética, apesar de possuir ilustres defensores ${ }^{37}$ e também de estar positivada no direito processual civil brasileiro, sofreu e sofre críticas de várias ordens. Calmon de Passos, por exemplo, afirma textualmente: "Jamais me conformei, teoricamente, com essa construção, que tenho como indefensável"138.

É verdade, por outro lado, que todas as teorias anteriormente expostas, em que pese tenham sido concebidas num momento histórico, social e econômico totalmente distinto da atualidade, sofrem (e merecem) críticas. Contudo, a teoria eclética, por ter sido acolhida com tanto entusiasmo e sem muitas ressalvas pelo direito processual brasileiro (sendo "erigida" até mesmo à condição de norma positivada), merece uma atenção mais articulada.

Ovídio Baptista da Silva e Fábio Luiz Gomes expõem o artificialismo da teoria eclética nos seguintes termos:

Para demonstrar a relevância e a praticidade do entendimento do conceito adequado de Ação, basta frisar um dos tantos aspectos que dele decorre, como, por exemplo, a maior ou menor amplitude do conceito de Jurisdição e a sua influencia sobre os limites objetivos da coisa julgada. A posição assumida pelos defensores da teoria eclética gera a conclusão segundo a qual nem todo pedido de tutela jurisdicional desencadeia o exercício de verdadeira Jurisdição. Assim, caso se verifique a ausência de uma das denominadas condições da Ação (possibilidade jurídica do pedido, legitimidade e interesse), deve o juiz negar-se a um pronunciamento sobre o mérito e sua atividade não poderá ser qualificada como jurisdicional.

37 DINARMARCO, Cândido Rangel. Instituições de direito processual civil, e THEODORO JÚNIOR, Humberto. Curso de direito processual civil: teoria geral do direito processual civil e Processo de conhecimento, apenas para citar dois processualistas brasileiros.

38 Esboço de uma teoria das nulidades aplicada às nulidades processuais. Rio de Janeiro: Forense, 2002. P. 117. 
BEDUSCHI, Leonardo. A ação na perspectiva do direito fundamental de acesso à tutela jurisdicional. Revista Eletrônica Direito e Política, Programa de Pós-Graduação Stricto Sensu em Ciência Jurídica da UNIVALI, Itajaí, v.10, n.2, $1^{0}$ quadrimestre de 2015. Disponível em: www.univali.br/direitoepolitica ISSN 1980-7791.

\begin{abstract}
Atentemos para o que preleciona o mentor dessa escola: "ausente uma destas condições, verifica-se o que, na exata expressão tradicional, se qualifica de carência de Ação e o juiz deve negar-se a prover sobre o mérito da demanda. Neste caso não haverá verdadeiro exercício da Jurisdição".

Segundo esta corrente, portanto, não havendo verdadeiro exercício de Jurisdição, não haverá falar em eficácia de coisa julgada imanente à sentença que julga o Processo extinto por ilegitimidade ad causam de qualquer das partes! $\mathrm{E}$, nessa mesma hipótese, não teria sequer havido "Ação", já que esta desencadeia sempre a Jurisdição. E mais ainda: a parte vencida poderia propor novamente a Ação! ${ }^{39}$
\end{abstract}

Os mencionados processualistas partem do pressuposto (a nosso ver correto) de que a atividade desenvolvida pelo juiz na apreciação das condições da Ação é uma atividade tipicamente jurisdicional, ao contrário do que sustenta Liebman, sendo essa a coluna central da sua crítica.

Expõem, ainda, que a teoria eclética representa uma tentativa de "conciliação do inconciliável", pois não se afiguraria possível a criação de um meio termo entre a teoria concreta e a teoria abstrata. Da mesma forma, aceitar a posição de Liebman significaria partir do pressuposto que existe uma atividade estatal de natureza diversa das três previstas na Constituição (executiva, legislativa e judiciária) que seria exercida pelo juiz ao decidir sobre as condições da Ação.

Os adeptos da teoria eclética, ao imputarem de absurdas as hipóteses nas quais o juiz teria de jurisdicionar por força de pedidos manifestamente injurídicos, não se dão conta de que estão a raciocinar no plano do direito material; com efeito, sob o prisma processual só se poderá falar de injuridicidade manifesta após a sentença; e esta só poderá ser proferida após o autor submeter a relação ao único órgão competente para tanto, com força vinculativa, qual seja o jurisdicional, vale dizer, após o autor agir propondo a Ação ${ }^{40}$.

Luiz Guilherme Marinoni fundamenta sua crítica no fato de que os fundamentos e conclusões da teoria eclética estão evidentemente alinhados com uma "dimensão meramente técnica e socialmente neutra do que com a possibilidade da sua efetivação num mundo real", de Direitos Fundamentais constitucionalizados e com uma configuração de sociedade totalmente diferente daquela na qual tal teoria foi

\footnotetext{
${ }^{39}$ SILVA, Ovídio Araújo Baptista da; GOMES, Fábio Luiz. Teoria geral do Processo civil, p. 92-93.

${ }^{40}$ SILVA, Ovídio Araújo Baptista da; GOMES, Fábio Luiz. Teoria geral do Processo civil, p. 119-121.
} 
BEDUSCHI, Leonardo. A ação na perspectiva do direito fundamental de acesso à tutela jurisdicional. Revista Eletrônica Direito e Política, Programa de Pós-Graduação Stricto Sensu em Ciência Jurídica da UNIVALI, Itajaí, v.10, n.2, 10 quadrimestre de 2015. Disponível em: www.univali.br/direitoepolitica ISSN 1980-7791.

concebida $^{41}$.

E pontua também nos seguintes termos, fazendo eco aos demais críticos da teoria eclética:

[....] Quer dizer que a sentença que reconheceu a inexistência de uma das condições da Ação extingue o Processo que foi instaurado pela própria Ação, o que significa que essa sentença, ainda que de extinção do Processo, admite que o Processo foi instaurado e a Ação proposta e que ambos se desenvolveram até um determinado instante, embora não tenha sido possível a apreciação do pedido. Portanto, mesmo quando verificada a ausência de uma das chamadas "condições da Ação", é inegável que a Jurisdição atuou e a Ação foi exercida. Aliás, a Jurisdição atuou porque a Ação foi proposta, o que se dá no momento em que a petição inicial é despachada pelo juiz ou distribuída (CPC, art. 263). Isso significa que não é correto dizer que só existe Ação e Jurisdição quando estão presentes as chamadas "condições da Ação" ${ }^{\prime 2}$.

Na verdade, a maior crítica que pode ser dirigida à teoria eclética pode se tornar também um elemento favorável à sua aceitação, que é o fato de que, se reconhecida a ausência das condições da Ação logo no início da demanda e a petição inicial for indeferida ( $e$, consequentemente, o Processo for extinto sem a resolução do mérito logo no seu nascedouro), ter-se-á a aplicação de uma medida de economia processual ${ }^{43}$, em que pese, ainda assim, restar sem explicação teórica o "caminho" que o autor utilizou até chegar ao pronunciamento judicial de carência de Ação.

\section{A AÇÃO HOJE}

Da exposição sucinta das principais teorias acerca da Ação é possível verificar que a preocupação com a realização do direito material ou com o acesso à justiça não estava na pauta dos teóricos desse período.

Em relação a esse tópico específico do acesso à justiça, traduzir o direito de Ação como a simples garantia formal de propor uma Ação em juízo, característica típica

\footnotetext{
41 MARIONI, Luiz Guilherme. Teoria geral do Processo, p. 184.

42 MARIONI, Luiz Guilherme. Teoria geral do Processo, p. 179-180.

43 "A menos quando se vê o preenchimento das condições da Ação como um garantia de que o Processo não se desenvolverá de forma inútil. Ou seja, quando se entende que as condições da Ação tem a sua função ligada ao princípio da economia processual - ou precisamente com a necessidade de impedir o desenvolvimento do Processo quando o juiz não pode julgar o mérito por faltar uma das condições da Ação (de forma inútil)-, quando não há qualquer lógica em admitir que o juiz declare a ausência de uma condição da Ação ao final do Processo, pois nesse caso se estará admitindo a sua inutilidade após dou ou três anos do seu início" (MARIONI, Luiz Guilherme. Teoria geral do Processo, p. 181).
} 
BEDUSCHI, Leonardo. A ação na perspectiva do direito fundamental de acesso à tutela jurisdicional. Revista Eletrônica Direito e Política, Programa de Pós-Graduação Stricto Sensu em Ciência Jurídica da UNIVALI, Itajaí, v.10, n.2, $1^{0}$ quadrimestre de 2015. Disponível em: www.univali.br/direitoepolitica ISSN 1980-7791.

de uma visão puramente liberal do Processo, não leva em conta os problemas que impedem que tal direito seja efetivamente exercido, mormente o custo do Processo e a demora processual, que tem por principais "vítimas" as pessoas que tem menos recursos, gerando uma verdadeira injustiça social ${ }^{44}$.

Tal concepção do direito de Ação tem raízes na própria configuração do Estado liberal clássico, que concebia os Direitos Fundamentais ${ }^{45}$ tão somente como direitos de liberdade ou direitos de defesa. Essa concepção de matiz nitidamente individualista (que será analisada no momento oportuno) gerou diversas críticas, que formam uma corrente caracterizada por um ceticismo intelectual em relação aos direitos humanos e fundamentais ${ }^{46}$.

Atualmente, o desaparecimento do Estado liberal clássico e a ascensão dos Estados sociais permitiram a visualização de novos Direitos Fundamentais os quais passaram a exigir do Estado ações ou prestações positivas ${ }^{47}$. Perceba-se que os direitos de defesa e de liberdade exigiam, quando muito, abstenções estatais, com o objetivo de impedir a agressão estatal sobre a esfera privada ${ }^{48}$, característica que não se coaduna com os denominados Direitos Fundamentais prestacionais, que exigem

\footnotetext{
44 MARIONI, Luiz Guilherme. Teoria geral do Processo, p. 185-186. E prossegue o referido autor: "Acusar os juízes pela demora da justiça constitui um reducionismo imperdoável, uma vez que a questão da demora passa por uma dimensão muito mais profunda, ou seja, pela própria ideologia que permite que o Poder Judiciário seja o que é, pois, como é intuitivo, nada possui uma determinada configuração sem razão ou motivo algum. Nessa dimensão nenhuma "justiça" é boa ou má, ou efetiva ou inefetiva, já que ela sempre será da "forma" que os detentores do poder a desejarem, e, portanto, para alguns, sempre "boa" e "efetiva"". (MARIONI, Luiz Guilherme. Teoria geral do Processo, p. 189190).

45 "Direitos Fundamentais são, portanto, todas aquelas posições jurídicas concernentes às pessoas que, do ponto de vista do direito constitucional positivo, foram, por seu conteúdo e importância (fundamentalidade em sentido material), integradas ao texto da Constituição e, portanto, retiradas da esfera de disponibilidade dos poderes constituídos (fundamentalidade em sentido formal), bem como as que, por seu conteúdo e significado, possam lhes ser equiparados, agregando-se à Constituição material, tendo, ou não, assento na Constituição formal (aqui considerada a abertura material do Catálogo)" (SARLET, Ingo Wolfgang. A eficácia dos Direitos Fundamentais: uma teoria geral dos Direitos Fundamentais na perspectiva constitucional. P. 77).
}

${ }^{46}$ Amartya Zen colaciona a crítica de Jeremy Bentham, para quem "os direitos naturais são simples absurdos; direitos naturais e imprescritíveis são absurdos retóricos, absurdos empolados" (ZEN, Amartya. A ideia de justiça. Tradução de Denise Bottmann e Ricardo Doninelli Mendes. São Paulo: Companhia das Letras, 2011. Título original: The Idea of Justice. P. 391).

47 "De acordo com a interpretação liberal clássica, Direitos Fundamentais são destinados, em primeira instância, a proteger a esfera de liberdade do indivíduo contra intervenções dos Poderes Públicos; eles são direitos de defesa do cidadão contra o Estado. Direitos de defesa do cidadão contra o Estado são direitos a ações negativas (abstenções) do Estados. Eles pertencem ao status negativo, mais precisamente ao status negativo em sentido amplo. Seu contraponto são os direitos a uma Ação positiva do Estado, que pertencem ao status positivo, mais precisamente ao status positivo em sentido estrito". (ALEXY, Robert. Teoria dos Direitos Fundamentais. Tradução de Virgílio Afonso da Silva. São Paulo: Malheiros, 2008. Título original: Theorie der Grundrechte. P. 433).

48 MARIONI, Luiz Guilherme. Teoria geral do Processo, p. 193. 
BEDUSCHI, Leonardo. A ação na perspectiva do direito fundamental de acesso à tutela jurisdicional. Revista Eletrônica Direito e Política, Programa de Pós-Graduação Stricto Sensu em Ciência Jurídica da UNIVALI, Itajaí, v.10, n.2, 10 quadrimestre de 2015. Disponível em: www.univali.br/direitoepolitica ISSN 1980-7791.

ações positivas por parte do Estado.

Os Direitos Fundamentais prestacionais podem ser divididos em prestações sociais, prestações de proteção e prestações destinadas a viabilizar a participação no poder e na organização estatal ${ }^{49}$, sendo que o exercício da Ação configura, "em si mesmo, a participação". Já o fim que nela se busca (a tutela jurisdicional) "é a prestação constitutiva do direito social" ${ }^{\prime 50}$.

Claro que a Ação não é (nem poderia ser) a única forma de participação. Entretanto, Owen Fiss sustenta que o acesso ao judiciário constitui um canal específico de participação em virtude do caráter dialógico do Processo judicial, pois o juiz somente está habilitado a exercer poder após ter participado de um diálogo acerca do significado dos valores públicos. Tal diálogo possui qualidades especiais:

(a) os juízes não controlam a sua própria agenda, pelo contrário, são compelidos a confrontar queixas e reivindicações que de outro modo eles prefeririam ignorar; (b) os juízes não tem controle pleno com respeito a quem eles querem devem ouvir. Eles são vinculados por regras que exigem que eles ouçam uma ampla gama de pessoas e porta-vozes; (c) os juízes são compelidos a retrucar, a responder a queixa ou a reivindicação, e assumir a responsabilidade individual por essa resposta; (d) os juízes devem também justificar suas decisões ${ }^{51}$.

E há que se considerar ainda, diante do dever estatal de proteção dos Direitos Fundamentais, que o direito de Ação também pode se constituir num direito de exigir uma prestação de proteção, e isso pode ser feito mediante "normas de direito, através de prestações de proteção fática e mediante proteção (ou a tutela)

49 MARIONI, Luiz Guilherme. Teoria geral do Processo, p. 194. Alexy classifica os direitos a prestações (em sentido amplo) em direitos a proteção, direitos a organização e procedimento, e direitos a prestações em sentido estrito (Teoria dos Direitos Fundamentais, p. 444).

50 "Note-se que a participação depende apenas do exercício do direito de Ação, enquanto a prestação social exige a concessão da tutela jurisdicional ao autor" (MARIONI, Luiz Guilherme. Teoria geral do Processo, p. 195). Discorrendo sobre essa configuração dos direitos prestacionais, Robert Alexy aponta que "direitos a procedimentos judiciais e administrativos são direitos essenciais a uma "proteção jurídica efetiva". É condição de uma proteção jurídica efetiva que o resultado do procedimento proteja os direitos materiais dos titulares de Direitos Fundamentais envolvidos. A essa proteção de direitos materiais deve ser vinculada a fórmula do Tribunal Constitucional Federal, que descreve a tarefa do direito procedimental da seguinte forma: "O direito procedimental serve à produção de decisões que sejam conformes à lei e, por esse ponto de vista, corretas, mas, para além disso, de decisões que, no âmbito dessa correção, sejam justas. Tudo isso indica que, no âmbito do procedimento, dois aspectos devem ser relacionados entre si: um procedimental e um material." (Teoria dos Direitos Fundamentais, p. 488).

51 FISS, Owen. The forms of justice. Harvard Law Review, Cambridge: Harvard University Press, v. 93, 1979, p. 13. 
BEDUSCHI, Leonardo. A ação na perspectiva do direito fundamental de acesso à tutela jurisdicional. Revista Eletrônica Direito e Política, Programa de Pós-Graduação Stricto Sensu em Ciência Jurídica da UNIVALI, Itajaí, v.10, n.2, 10 quadrimestre de 2015. Disponível em: www.univali.br/direitoepolitica ISSN 1980-7791.

jurisdicional" ${ }^{52}$.

Consequentemente, se o Estado tem o dever de criar normas de proteção dos Direitos Fundamentais, ele também deve supor que tais normas podem ser transgredidas, pois seria muita ingenuidade imaginar que tal dever de proteção é plenamente cumprido com a simples proclamação dessas normas. Isso significa que o Estado, além de editar tais normas protetivas, que coíbem condutas contrárias a Direitos Fundamentais, deve também "instituir regras procedimentais instituintes de técnicas capazes de permitir a atuação efetiva e tempestiva do desejo de tais normas" pois, nesse sentido, se pode falar em "normas de proteção de direito material e normas de proteção de direito processual" ${ }^{\prime 53}$.

E o direito de Ação, nesse contexto, ganha uma relevância especial, pois o grande problema, "diante do dever de proteção do Estado, aparece quando se pensa na insuficiência de proteção do administrador e especialmente do legislador" ${ }^{\prime 54}$.

\section{CONSIDERAÇÕES FINAIS}

Espera-se ter evidenciado, com essa breve digressão, que a preocupação em assegurar uma participação efetiva por meio do Processo e o dever de proteção dos Direitos Fundamentais colocam o problema do conceito da Ação num patamar muito distante daquele no qual se encontram as teorias que discutiam sobre a abstração e a autonomia do direito de Ação.

Aquelas teorias tiveram seu tempo e o seu lugar. Atualmente, a sociedade e o Estado possuem uma configuração diversa daquela na qual tais teorias foram concebidas, de modo que é indispensável pensar-se num conceito da categoria Ação que revele a preocupação com o efetivo acesso à ordem jurídica justa, e não apenas com o direito formal de acesso ao judiciário.

\footnotetext{
52 MARIONI, Luiz Guilherme. Teoria geral do Processo, p. 199.

53 MARIONI, Luiz Guilherme. Teoria geral do Processo, p. 201. No mesmo sentido, Ingo Sarlet afirma que os Direitos Fundamentais são dependentes da organização e do procedimento, mas também sobre estes exercem influência que "se manifesta na medida em que os Direitos Fundamentais podem ser considerados como parâmetro para a formatação das estruturas organizatórias e dos procedimentos, servindo, para alem disso, como diretrizes para a aplicação e interpretação das normas procedimentais". (SARLET, Ingo Wolfgang. A eficácia dos Direitos Fundamentais: uma teoria geral dos Direitos Fundamentais na perspectiva constitucional, p. 194). Em relação a esse aspecto específico dos Direitos Fundamentais, Carlos Alberto Álvaro de Oliveira aponta o seu caráter principiológico, que se destina "a iluminar as regras já existentes, permitindo ao mesmo tempo a formulação de outras regras específicas para solucionar questões processuais pendentes" (OLIVEIRA, Carlos Alberto Álvaro de. O Processo civil na perspectiva dos Direitos Fundamentais. In: DIDIER JR, Fredie (org.). Leituras complementares de Processo civil. 7. ed. Salvador: Juspodivm, 2009, p. 113).
}

${ }^{54}$ MARIONI, Luiz Guilherme. Teoria geral do Processo, p. 203. 
BEDUSCHI, Leonardo. A ação na perspectiva do direito fundamental de acesso à tutela jurisdicional. Revista Eletrônica Direito e Política, Programa de Pós-Graduação Stricto Sensu em Ciência Jurídica da UNIVALI, Itajaí, v.10, n.2, 10 quadrimestre de 2015. Disponível em: www.univali.br/direitoepolitica ISSN 1980-7791.

Com a finalidade de alcançar esse conceito, parte-se do pressuposto que o conceito de Ação é, atualmente, multifacetado, vinculando não apenas o judiciário, mas todos os poderes constitucionais. Assim, sob a ótica do legislativo, o direito fundamental de Ação determina a criação de técnicas processuais idôneas à efetiva tutela jurisdicional do direito material, ou seja, o legislador está obrigado a "traçar técnicas processuais capazes de permitir a proteção de diversas situações conflitivas" ${ }^{\prime 55}$.

Naturalmente, por outro lado, o maior obrigado em relação ao direito fundamental de Ação é o Estado-juiz, pois é o juiz que tem o dever de prestar a adequada tutela jurisdicional dos direitos, mediante o emprego da interpretação de acordo com a Constituição e das técnicas de controle de constitucionalidade da lei que estiver aplicando. Sob esta ótica, o direito de Ação pode ser decomposto em três aspectos básicos: direito de acesso à Jurisdição, direito ao Processo justo e direito à técnica processual adequada, sendo que nenhum desses aspectos pode ser considerado de forma isolada ${ }^{56}$.

É importante também destacar o que a Ação não é (ou, não é apenas):

[...] o direito de Ação não é apenas o direito de afirmar um direito material em juízo ou o direito de formular um pedido de tutela do direito material com base em fundamentos de fato e de direito. A Ação não se resume ao ato que invoca a jurisdição. Não é um ato solitário, como se o direito de Ação pudesse ser restringido a um requerimento de tutela jurisdicional. ${ }^{57}$

O que importa é demonstrar que a Ação, no Estado constitucional, não pode ignorar a estrutura do procedimento. Ou seja, deve haver a necessária conformação do procedimento, ainda que a partir de uma cláusula processual aberta, para a efetiva proteção do direito material. Portanto, a norma constitucional que afirma que a lei não excluirá da apreciação do Poder Judiciário lesão ou ameaça a direito (CF, art. $5 .^{\circ}, \mathrm{XXXV}$ ) significa, de uma só vez, que:

i) o autor tem o direito de afirmar lesão ou ameaça a direito; ii) o autor tem o direito de ver essa afirmação apreciada pelo juiz quando presentes os requisitos chamados de condições da Ação pelo art. 267, VI, do CPC; iii) o autor tem o direito de pedir a apreciação dessa afirmação, ainda que um desses requisitos esteja ausente; iv) a sentença que declara a ausência de uma condição da Ação não nega que o direito de pedir a apreciação da afirmação de lesão ou de ameaça foi

\footnotetext{
${ }^{55}$ MARIONI, Luiz Guilherme. Teoria geral do Processo, p. 207.

56 MARIONI, Luiz Guilherme. Teoria geral do Processo, p. 210-211.

57 MARIONI, Luiz Guilherme. Teoria geral do Processo, p. 215-216.
} 
BEDUSCHI, Leonardo. A ação na perspectiva do direito fundamental de acesso à tutela jurisdicional. Revista Eletrônica Direito e Política, Programa de Pós-Graduação Stricto Sensu em Ciência Jurídica da UNIVALI, Itajaí, v.10, n.2, 10 quadrimestre de 2015. Disponível em: www.univali.br/direitoepolitica ISSN 1980-7791.

exercido ou que a Ação foi proposta e se desenvolveu ou for exercitada; v) o autor tem o direito de influir sobre o convencimento do juízo mediante alegações, provas e, se for o caso, recurso; vi) o autor tem o direito à sentença e ao meio executivo capaz de dar plena efetividade à tutela jurisdicional por ela concedido; vii) o autor tem o direito à antecipação e à segurança da tutela jurisdicional; e viii) o autor tem o direito ao procedimento adequado à situação de direito substancial carente de proteção ${ }^{58}$.

Portanto, espera-se ter evidenciado o quão distante está, atualmente, o conceito de Ação daquela concepção ultrapassada que o considerava satisfeito com a singela invocação da prestação jurisdicional.

Isso porque, repita-se, não se pode admitir que os Direitos Fundamentais sejam reduzidos a proclamações meramente políticas, ou, em outras palavras, que sejam destituídos de eficácia e incidência prática. E é exatamente para reforçar estes novos delineamentos do constitucionalismo democrático, expressamente contemplados na Constituição Federal de 1988, e seus desdobramentos, que se afigura importante a adequada compreensão do direito à tutela jurisdicional como um Direito Fundamental.

Não se trata, por certo, de uma visão meramente cosmética, baseada na retórica poderosa do discurso dos Direitos Fundamentais. Na verdade, os grandes problemas que cercam os Direitos Fundamentais são justamente o excesso de discurso aliado à carência de concretização.

Merece ser destacada, nesse contexto, a visão de Luigi Ferrajoli que, após expor sua concepção sobre a necessidade de superação da "democracia plebiscitária", consubstanciada na supremacia da maioria, e caracterizar os Direitos Fundamentais como o núcleo da "democracia constitucional", que pertenceriam à "esfera do indecidível" ${ }^{\prime 59}$, se pergunta quais são os Direitos Fundamentais? A esta pergunta o aludido autor dá três respostas distintas ${ }^{60}$.

A primeira resposta é a que oferece a teoria do direito. No plano teórico-jurídico a definição mais fecunda de Direitos Fundamentais é a que os identifica com os

\footnotetext{
58 MARIONI, Luiz Guilherme. Teoria geral do Processo, p. 221.

59 Adotando mais ou menos a mesma orientação, Francisco José de Oliveira Neto expõe que "os direitos fundamentais apresentam-se como elemento central que caracteriza o Estado Constitucional de Direito, não sendo exagero algum afirmar que a proteção a esses direitos constitui-se no principal objetivo de sua existência" (OLIVEIRA NETO, Francisco José de. Estrita legalidade e atividade jurisdicional [recurso eletrônico]. Itajaí: UNIVALI, 2012 (Coleção Osvaldo Ferreira de Melo; v. 6). Disponível em <http://univali.br/ppcj/ebook>. Acesso em 2 de outubro de 2012, p. 20).
}

${ }^{60}$ FERRAJOLI, Luigi. Democracia y garantismo. Tradução de Perfecto Andrés Ibáñes, et al. Madrid: Trotta, 2008. P. 42. 
BEDUSCHI, Leonardo. A ação na perspectiva do direito fundamental de acesso à tutela jurisdicional. Revista Eletrônica Direito e Política, Programa de Pós-Graduação Stricto Sensu em Ciência Jurídica da UNIVALI, Itajaí, v.10, n.2, $1^{0}$ quadrimestre de 2015. Disponível em: www.univali.br/direitoepolitica ISSN 1980-7791.

direitos que estão atribuídos universalmente a todos enquanto pessoas, ou enquanto cidadãos ou pessoas com capacidade de trabalhar, e que são, portanto, indisponíveis e inalienáveis. A segunda resposta é a que oferece o direito positivo, ou seja, a dogmática constitucional ou internacional. São Direitos Fundamentais, no ordenamento italiano ou alemão, os direitos universais e indisponíveis estabelecidos pelo direito positivo italiano ou alemão. São Direitos Fundamentais, no ordenamento internacional, os direitos universais e disponíveis estabelecidos na Declaração Universal dos Direitos Humanos de 1948, nos pactos internacionais de 1966 e nas demais convenções internacionais sobre os direitos humanos. A terceira resposta, que será abordada adiante, é a que oferece a filosofia política, e se reflete na pergunta de "que direitos devem ser garantidos como fundamentais". Para fundamentá-la racionalmente devem ser formulados critérios meta-éticos e metapolíticos idôneos para identificá-los. Sumariamente, parecem que podem ser indicados três critérios axiológicos, sugeridos pela experiência histórica do constitucionalismo estatal e internacional $^{61}$.

O primeiro desses critérios é o nexo entre os direitos humanos e a paz, instituído no preâmbulo da Declaração Universal de 1948. Sob esse ponto de vista, devem ser garantidos como Direitos Fundamentais todos os direitos vitais cuja garantia é condição necessária para a paz: o direito à vida e à integridade pessoal, os direitos civis e políticos, os direitos de liberdade, mas também, num mundo em que sobreviver é cada vez menos um feito natural e cada vez mais um feito artificial, os direitos sociais para a sobrevivência. O segundo critério, particularmente relevante para o tema dos direitos das minorias, é o nexo entre direitos e igualdade. A igualdade é em primeiro lugar igualdade entre direitos de liberdade que garantam, em igual valor de todas as diferenças pessoais - de nacionalidade, de sexo, de língua, de opiniões políticas, de condições pessoais e sociais, como diz o artigo 30 parágrafo $1^{0}$ da Constituição Italiana - que fazem de cada pessoa um indivíduo diferente de todos os demais e de cada indivíduo uma pessoa igual a todas as outras; e é, em segundo lugar, igualdade nos direitos sociais, que garantam a redução das desigualdades econômicas e sociais. O terceiro critério é o papel dos Direitos Fundamentais como leis do mais fraco. Todos os Direitos Fundamentais são leis do mais fraco como alternativa à lei do mais forte que vigoraria em sua ausência: em primeiro lugar o direito à vida, contra a lei de quem é mais forte fisicamente; em segundo lugar os direitos de imunidade e de liberdade contra 0 arbítrio de quem é mais forte politicamente; em terceiro lugar os direitos sociais, que são direitos à sobrevivência contra a lei de quem é mais forte social e economicamente ${ }^{62}$.

Portanto, nesse contexto, é importante ver na norma contida no art. 50, inc. XXXV, da Constituição Federal, um direito formal e materialmente fundamental, que, por possuir eficácia imediata, precisa ser concretizado em cada demanda apreciada pelo

\footnotetext{
${ }^{61}$ FERRAJOLI, Luigi. Democracia y garantismo. P. 43-44.

62 FERRAJOLI, Luigi. Democracia y garantismo. P. 42-44.
} 
Poder Judiciário, sob pena de violação da norma em questão e redução do seu texto ao já referido, conhecido e inócuo discurso.

E para o desiderato de obter a afirmação e a realização dos Direitos Fundamentais é importante que o juiz esteja ciente do seu dever constitucional de adequar 0 procedimento ao caso concreto e à realidade social nele estampada, através do emprego da técnica processual que possibilite uma efetiva tutela dos direitos.

Do contrário, não se estará respeitando o Direito Fundamental de acesso à tutela jurisdicional, que deve ter sua Efetividade assegurada em cada caso concreto.

\section{REFERÊNCIAS DAS FONTES CITADAS}

ALEXY, Robert. Teoria dos Direitos Fundamentais. Tradução de Virgílio Afonso da Silva. São Paulo: Malheiros, 2008. Título original: Theorie der Grundrechte.

BEDUSCHI, Leonardo. A adoção de cláusulas gerais processuais e a flexibilização das formas processuais como decorrências do princípio do acesso à ordem jurídica justa [recurso eletrônico]. Santa Cruz do Sul: Essere nel Mondo, 2014.

BEDUSCHI, Leonardo; HÜLSE, Levi. Anotações sobre a evolução do conceito de jurisdição. Revista Eletrônica Direito e Política, Programa de Pós-Graduação Stricto Sensu em Ciência Jurídica da UNIVALI, Itajaí, v.8, n.3, 30 quadrimestre de 2013. Disponível em: www.univali.br/direitoepolitica - ISSN 1980-7791.

CHIOVENDA, Giuseppe. Instituições de direito processual civil. Campinas : Bookseller, 1998. 1v. Título original: Instituizioni di Diritto Processuale Civile.

COUTURE, Eduardo J. Fundamentos del derecho procesal civil. 3. ed. póst. Buenos Aires : Depalma, 1973.

DINARMARCO, Cândido Rangel. Instituições de direito processual civil. 4. ed. São Paulo: Malheiros, 2004. Vol. I.

FERRAJOLI, Luigi. Democracia y garantismo. Tradução de Perfecto Andrés Ibáñes, et al. Madrid: Trotta, 2008.

FISS, Owen. The forms of justice. Harvard Law Review, Cambridge: Harvard University Press, v. 93, 1979, p. 13.

MARINONI, Luiz Guilherme. Teoria geral do Processo. São Paulo: RT, 2006

OLIVEIRA, Carlos Alberto Álvaro de. O Processo civil na perspectiva dos

Direitos Fundamentais. In: DIDIER JR, Fredie (org.). Leituras complementares de 

Revista Eletrônica Direito e Política, Programa de Pós-Graduação Stricto Sensu em Ciência Jurídica da UNIVALI, Itajaí, v.10, n.2, $1^{\circ}$ quadrimestre de 2015. Disponível em: www.univali.br/direitoepolitica ISSN 1980-7791.

Processo civil. 7. ed. Salvador: Juspodivm, 2009.

OLIVEIRA NETO, Francisco José de. Estrita legalidade e atividade jurisdicional [recurso eletrônico]. Itajaí: UNIVALI, 2012 (Coleção Osvaldo Ferreira de Melo; v. 6). Disponível em <http://univali.br/ppcj/ebook>. Acesso em 2 de outubro de 2012

PASSOS, Joaquim José Calmon de. Esboço de uma teoria das nulidades aplicada às nulidades processuais. Rio de Janeiro: Forense, 2002. P. 117.

PINHO, Humberto Dalla Bernardina de. Direito processual civil contemporâneo. Volume I. 4. ed. 2a tir. São Paulo: Saraiva, 2012.

SANTOS, Moacyr Amaral; KÖHNEN, Maria Beatriz Amaral Santos. Primeiras linhas de direito processual civil. 27. ed. São Paulo : Saraiva, 2010.

\section{SARLET, Ingo Wolfgang. A eficácia dos Direitos Fundamentais: uma teoria geral dos Direitos Fundamentais na perspectiva constitucional}

SILVA, Ovídio Araújo Baptista da; GOMES, Fábio Luiz. Teoria geral do Processo civil.4. ed. rev. e atual. com a recente reforma processual. São Paulo : Revista dos Tribunais, 2006.

THEODORO JÚNIOR, Humberto. Curso de direito processual civil: teoria geral do direito processual civil e Processo de conhecimento.53. ed. rev. e atual., Rio de Janeiro : Forense, 2012.

WINDSCHEID, Bernard e MUTHER, Theodor. Polemica sobre la "Actio". Buenos Aires: Ediciones Juridicas Europa-America (EJEA), 1974.

ZAGREBELSKY, Gustavo. El Derecho Dúctil: ley, derechos, justicia. Tradução de Marina Gascón. 6. ed. Madrid: Editorial Trotta, 2005. Título original: Il diritto mitte. Legge diritti giustizia.

ZEN, Amartya. A ideia de justiça. Tradução de Denise Bottmann e Ricardo Doninelli Mendes. São Paulo: Companhia das Letras, 2011. Título original: The Idea of Justice.

Submetido em: Janeiro/2015

Aprovado em: Março/2015 